\title{
Entrevista al Dr. Marcelo Lopes de Souza: "Los desafíos contemporáneos ofrecen a la Geografía una oportunidad única para demostrar su relevancia social"
}

\author{
Interview with Dr. Marcelo Lopes de Souza: "Contemporary challenges \\ offer Geography a unique opportunity to demonstrate its social relevance"

\section{Entrevista com Dr. Marcelo Lopes de Souza: “Os desafios contemporâneos oferecem à Geografia uma oportunidade única de demonstrar sua relevância social"}

\author{
Victor A. Huaytalla L. \\ Universidad Nacional Mayor de San Marcos, Universidad Nacional Agraria \\ La Molina, Unión Geográfica Internacional Perú (UGI-Perú). \\ v.huaytalla.geo@gmail.com - https://orcid.org/0000-0003-2066-6806
}

\begin{abstract}
RESUMEN
Marcelo Lopes de Souza es bacharel y mestre en Geografía por la Universidad Federal de Rio de Janeiro. Realizó su doctorado en Geografía en la Universität Tübingen (Alemania) y ha sido invitado como profesor en diferentes universidades de Europa y América Latina. Actualmente es profesor titular de la Universidad Federal de Río de Janeiro y coordinador del Centro de Investigación en Geografía Ambiental y Ecología Política (GAEP), vinculado al Departamento de Geografía de la misma universidad. Su interés académico se centra en el estudio de los vínculos entre el cambio social y la organización espacial. Es autor u organizador de diecisiete libros (trece publicados en Brasil, uno en Alemania y tres en Inglaterra) y casi ciento cincuenta artículos y capítulos de libros. En esta entrevista nos comparte sus ideas sobre la situación social y política de Brasil frente a la pandemia generada por la COVID-19 y las contribuciones que la geografía debería brindar. De igual forma, expone su pensamiento acerca del desarrollo y evolución de la geografía brasileña. También da a conocer su interés y producción académica centrada en la Geografía Ambiental, la Ecología Política, la relación espacio y naturaleza desde la perspectiva libertaria, las luchas sociales, la justicia ambiental como dimensión del desarrollo socio-espacial, entre otros. Por último, concluye resaltando la necesidad de cooperación entre los geógrafos y los movimientos sociales frente a la desigualdad y la injusticia ambiental; no solo participando como agentes académicos, sino, mediante el activismo, y el desarrollo de conocimientos útiles y colaborativos.
\end{abstract}

\begin{abstract}
Marcelo Lopes de Souza is a Bachelor and Master in Geography from the Federal University of Rio de Janeiro. He completed his doctorate in Geography at the Universität Tübingen (Germany) and has been invited as a professor at different universities in Europe and Latin America. He is currently a tenured professor at the Federal University of Rio de Janeiro and coordinator of the Center for Research in Environmental Geography and Political Ecology (GAEP), linked to the Department of Geography of the same university. His academic interest focuses on the study of the links between social change and spatial organization. He is the author or organizer of seventeen books (thirteen published in Brazil, one
\end{abstract}

Recibido:15/09/2020 - Aceptado: 25/09/2020 - Publicado: 22/02/2021

Citar como:

Huaytalla, V. (2020). Entrevista al Dr. Marcelo Lopes de Souza: "Los desafíos contemporáneos ofrecen a la Geografía una oportunidad única para demostrar su relevancia social”. Espiral, revista de geografías y ciencias sociales, 2(4), 195 - 212. http:// dx.doi.org/10.15381/espiral.v2i4.19538

C Los autores. Este artículo es publicado por Espiral, revista de geografías y ciencias sociales de la Universidad Nacional Mayor de San Marcos. Este es un artículo de acceso abierto, distribuido bajo los términos de la licencia Creative Commons Atribucion- No Comercia_Compartir Igual 4.0 Internacional. (http://creativecommons.org/licenses/by-nc-sa/4.0/) que permite el uso no comercial, distribución y reproducción en cualquier medio, siempre que la obra original sea debidamente citada. 
in Germany, and three in England) and nearly one hundred and fifty articles and book chapters. In this interview, he shares his ideas about the social and political situation in Brazil in the face of the pandemic generated by COVID-19 and the contributions that geography should provide. In the same way, he exposes his thoughts about the development and evolution of the Brazilian geography. He also makes known his interest and academic production focused on Environmental Geography, Political Ecology, the relationship between space and nature from the libertarian perspective, social struggles, environmental justice as a dimension of socio-spatial development, among others. Finally, he concludes by highlighting the need for cooperation between geographers and social movements in the face of inequality and environmental injustice; not only participating as academic agents, but also through activism and the development of useful and collaborative knowledge.

\section{RESUMO}

Marcelo Lopes de Souza é Bacharel e Mestre em Geografia pela Universidade Federal do Rio de Janeiro. Ele completou seu doutorado em Geografia na Universität Tübingen (Alemanha) e foi convidado como professor em diferentes universidades da Europa e América Latina. Atualmente é professor titular da Universidade Federal do Rio de Janeiro e coordenador do Centro de Pesquisas em Geografia Ambiental e Ecologia Política (GAEP), vinculado ao Departamento de Geografia da mesma universidade. Seu interesse acadêmico se concentra no estudo das ligações entre mudança social e organização espacial. É autor ou organizador de dezessete livros (treze publicados no Brasil, um na Alemanha e três na Inglaterra) e quase cento e cinquenta artigos e capítulos de livros. Nesta entrevista, ele compartilha suas ideias sobre a situação social e política do Brasil frente à pandemia gerada pelo COVID-19 e as contribuições que a geografia deve proporcionar. Da mesma forma, expõe seu pensamento sobre o desenvolvimento e a evolução da geografia brasileira. Também dá a conhecer o seu interesse e produção acadêmica voltada para a Geografia Ambiental, Ecologia Política, a relação entre o espaço e a natureza na perspectiva libertária, as lutas sociais, a justiça ambiental como dimensão do desenvolvimento socioespacial, entre outras. Por fim, ele conclui destacando a necessidade de cooperação entre geógrafos e movimentos sociais diante da desigualdade e da injustiça ambiental; não apenas participando como agentes acadêmicos, mas também por meio do ativismo e do desenvolvimento de conhecimentos úteis e colaborativos.

PALABRAS CLAVES: COVID-19; geografía brasileña; Geografía Ambiental; pensamiento libertario.

KEYWORDS: COVID-19; Brazilian geography; Environmental Geography; libertarian thought.

PALAVRAS-CHAVE: COVID-19; geografia brasileira; geografia ambiental; pensamento libertário.

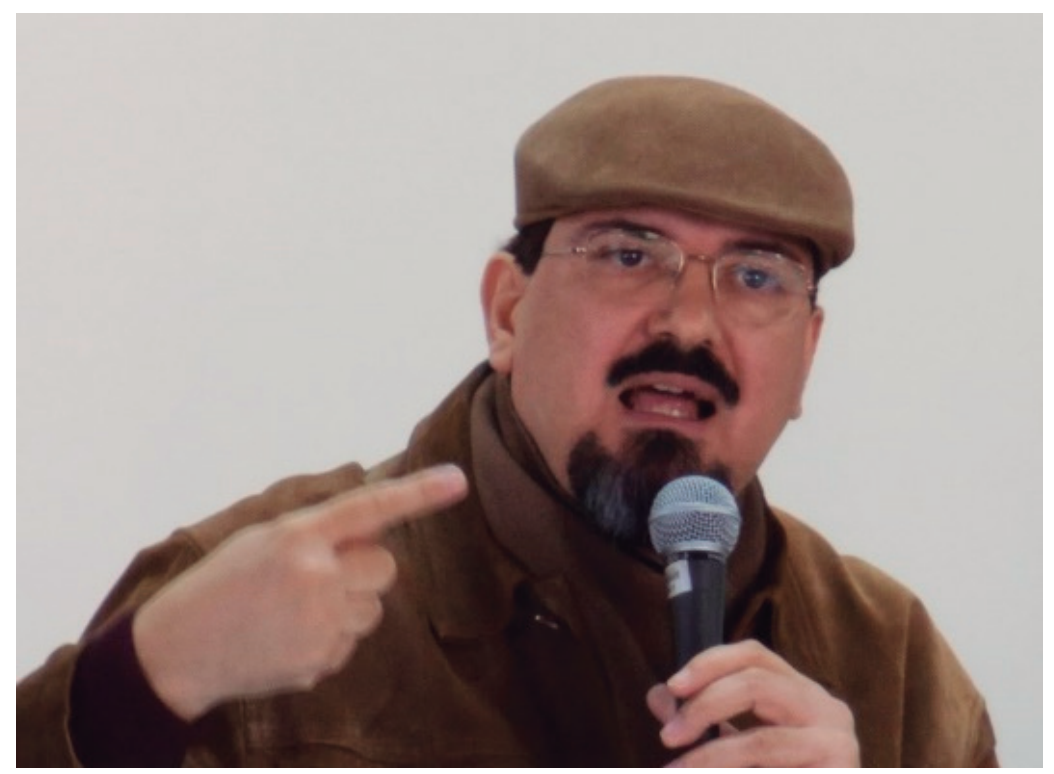

Figura 1. Marcelo Lopes de Souza durante una conferencia en 2011.

VH: La gestión de una pandemia es abordada en preparación y respuesta, es decir, las acciones se dan antes (con mayor incertidumbre), durante y después de que acontezca. El fin es evitar y reducir los impactos en la salud humana y en la economía. Sin embargo, la Covid-19 materializó 
ese nivel alto de incertidumbre convirtiendo "lo que pudo suceder" en lo que sucedió realmente; sucesos que observamos hasta estos días. Impactó al mundo no solo en el campo de la salubridad, tuvo la capacidad de paralizar la economía global, afectar la economía familiar, empujar a la sociedad hacia una nueva convivencia (diferente a generar cambios estructurales), entre otros. En general los impactos sucedieron ampliamente en las dimensiones social, político, económico, incluso ambiental. En ese sentido, le pregunto: además de los mapas, ¿cuál es o tendría que ser la contribución de la geografía (y los geógrafos) para entender y actuar frente al contexto actual de la pandemia?

MLS: Primero, es necesario aclarar que el geógrafo no es un cartógrafo; para los geógrafos, los mapas son medios, no fines en sí mismos.

Desde que la epidemia de COVID-19 comenzó a extenderse por todo el mundo - y dejando claro que todos enfrentaríamos una tragedia importante, la Organización Mundial de la Salud (OMS) la llevó al estado de pandemia el 11 de marzo de 2020 -, los geógrafos de muchos países comenzaron a movilizarse en torno al tema. Uno de los primeros en hablar públicamente fue David Harvey, con su artículo "Anti-capitalist politics in the time of COVID-19", y muchos otros lo siguieron rápidamente. En Brasil, entre varias otras iniciativas, tuvimos las dos partes del "Dossiê Coronavirus" de la revista Espaço e Economia: Revista Brasileira de Geografia Econômica, con un total de 38 artículos.

La riqueza de intervenciones que se está constituyendo, que abarca desde ejemplos muy buenos de análisis de la conjuntura hasta reflexiones con densidad teórica y conceptual, es indudablemente relevante. Sin embargo, un tipo fundamental de contribución no parece estar adecuadamente ofrecido: análisis basados en estudios sistemáticos e investigaciones empíricas de larga duración. Trabajos como los del geógrafo brasileño Raúl Borges Guimarães, de la UNESP, a veces en coautoría con colegas en el campo de las ciencias biomédicas, son raros. Pero eso no es sorprendente: ¿cuántos geógrafos se han dedicado a la investigación en la interfaz entre Geografía de la Salud, Estudios Urbanos y Epidemiología Ambiental? Una cosa es meditar sobre la magnitud y las características del desafío representado por COVID-19, proporcionando un análisis provocativo y algunos insights interesantes (que, en algunos casos, sin embargo, los podría ofrecer un sociólogo, un filósofo o incluso un buen periodista); otra cosa, basada en muchos años de investigación en el contexto de esas interfaces, es proporcionar subsidios para pensar en detalles socioespaciales (y operativos), hacer pronósticos consistentes y discutir las deficiencias político-gerenciales de una situación que tiene una estructura y toda una historia de elitismo, autoritarismo y racismo detrás de ella. Para expresar opiniones sensatas y proporcionar reflexiones interesantes, la inteligencia (con un mínimo de información, obviamente) a menudo es suficiente, mientras que, para expresar juicios sólidos y detallados sobre algo, es esencial tener experiencia acumulada, tanto técnica-metodológica como empírica. Es el tipo de experiencia que no se obtiene en cuestión de semanas o meses.

La importancia de la Geografía de la Salud, en el marco del problema de la pandemia de COVID-19, proporciona un pretexto para insistir en la relevancia de considerar la integración de los aportes de geógrafos humanos y físicos, así como en el precio que se pagará por décadas de descuido con respecto a esta integración, en la formación de los geógrafos. La Geografía de la Salud es sólo una ilustración de esa relevancia, ya que sus objetos de conocimiento son, por lo general, "híbridos", y no se la puede practicar sin interfaces como las indicadas anteriormente. Desafíos como el de la injusticia ambiental, que se manifiestan a través de condiciones en las que se entrelazan la contaminación y/o los desastres, el sufrimiento ambiental (físico y psicológico), la segregación residencial (con sus muchos aspectos, como la falta de saneamiento básico y la vulnerabilidad social), son temas clave en una agenda que incluye no solo la Geografía de la Salud, sino también otros tipos de investigación, alimentados por 
la interfaz del conocimiento geográfico con los de Ecotoxicología, Epidemiología Ambiental y Social, etc.

Ahora, ¿en qué consiste la "geograficidad" de la pandemia? Consiste, por decirlo muy brevemente, en las características y condiciones relacionadas con los ecosistemas y los procesos geoecológicos, las tecnologías, la organización espacial y la producción social del espacio que influyen, de manera diferente según la escala y el lugar, en la dinámica "eco-social" de la enfermedad y sus condicionantes económicos, (socio) políticos y de comportamiento/culturales. Ahora, esta "geograficidad" requiere, para ser capturada sin comprometer su integridad, la integración del punto de vista sociogeográfico con el ecogeográfico.

VH: ¿Cuál es su opinión al respecto sobre el actuar de los países de América Latina (u otros) en respuesta a la Covid-19?

MLS: No conozco detalles sobre las acciones de los gobiernos de otros países de América Latina. Por supuesto, he seguido la situación en nuestro continente y el mundo a través de periódicos y otras fuentes de información, pero no me siento en condiciones de opinar sobre los casos concretos de otros países. Sin embargo, que yo sepa, la situación de Brasil es una de las peores del mundo.

Se ha convertido en un lugar común por parte de la izquierda brasileña reconocer que Brasil ha estado plagado no por uno, sino por dos virus: el coronavirus y el "virus" del (neo)fascismo. Este último, de hecho, ha agravado enormemente los problemas derivados del primero, además de traer sus propios desafíos (en términos de problemas políticos y de comportamiento/culturales, además de las consecuencias en forma de desigualdades económicas crecientes).

Un régimen como el de Bolsonaro así estaba realmente destinado a contribuir a la situación que vivimos actualmente en Brasil: la tragedia del COVID-19 se descontrola cada vez más, en medio de las tensiones diarias entre el Ejecutivo y los otros dos poderes del Estado (Poder Legislativo y Judicial), entre el gobierno y la prensa, entre el gobierno y la sociedad civil y, por último, pero no menos importante, entre el gobierno federal y los otros dos niveles del Ejecutivo (gobiernos de los estados y municipales). Una creciente presencia de personal militar en el gobierno federal, que ocupa cargos técnicos incluso en el Ministerio de Salud, no ha colaborado para estabilizar la situación política, por el contrario. En el momento de esta entrevista (comienzo de agosto de 2020), ya estamos con cien mil muertos y - debido a una flexibilización irresponsable y prematura de las medidas de aislamiento social - Brasil quizás va a experimentar una terrible "segunda ola" de la pandemia. Ya ocupando la segunda posición en el mundo en términos de casos y muertes totales, solo detrás de Estados Unidos, algunas fuentes estiman que Brasil podría convertirse en el verdadero "epicentro" global de la pandemia muy pronto.

A medida que avanza la tragedia, la asimetría social que revela (pero que siempre ha existido) se hace cada vez más evidente. Sobre todo, son los trabajadores pobres, que dependen del transporte colectivo (trenes, autobuses, metro) y que viven hacinados en favelas (barrios marginales), los que están siendo y serán cada vez más afectados. Entre ellos, especialmente en las regiones del sudeste y noreste del país, la mayoría de los pobres son afrobrasileños, históricamente víctimas del racismo. La tragedia de la pandemia en Brasil es seguramente general; pero al mismo tiempo, en su dimensión más característicamente "genocida", afecta principalmente a la clase trabajadora y la población afrodescendiente. Las favelas y las periferias pobres de las grandes ciudades ya se están viendo afectadas de manera desproporcionada, y es probable que esta tendencia se acentúe cada vez más con el tiempo. Además de aspectos muy generales, válidos para todo el mundo, como los efectos de la pandemia en términos de control socioespacial y crisis económica - también muy visible en Brasil -, existe 
una espacialidad específica de la pandemia de COVID-19 en un país como Brasil, que apunta a la tasa de mortalidad de enorme magnitud que se está produciendo paulatinamente en los espacios segregados de las grandes ciudades (en un país donde el 90\% de la población es considerada urbana). Esta es la "geograficidad" de la auténtica necropolítica neofascista actual en Brasil, en el contexto de la pandemia.

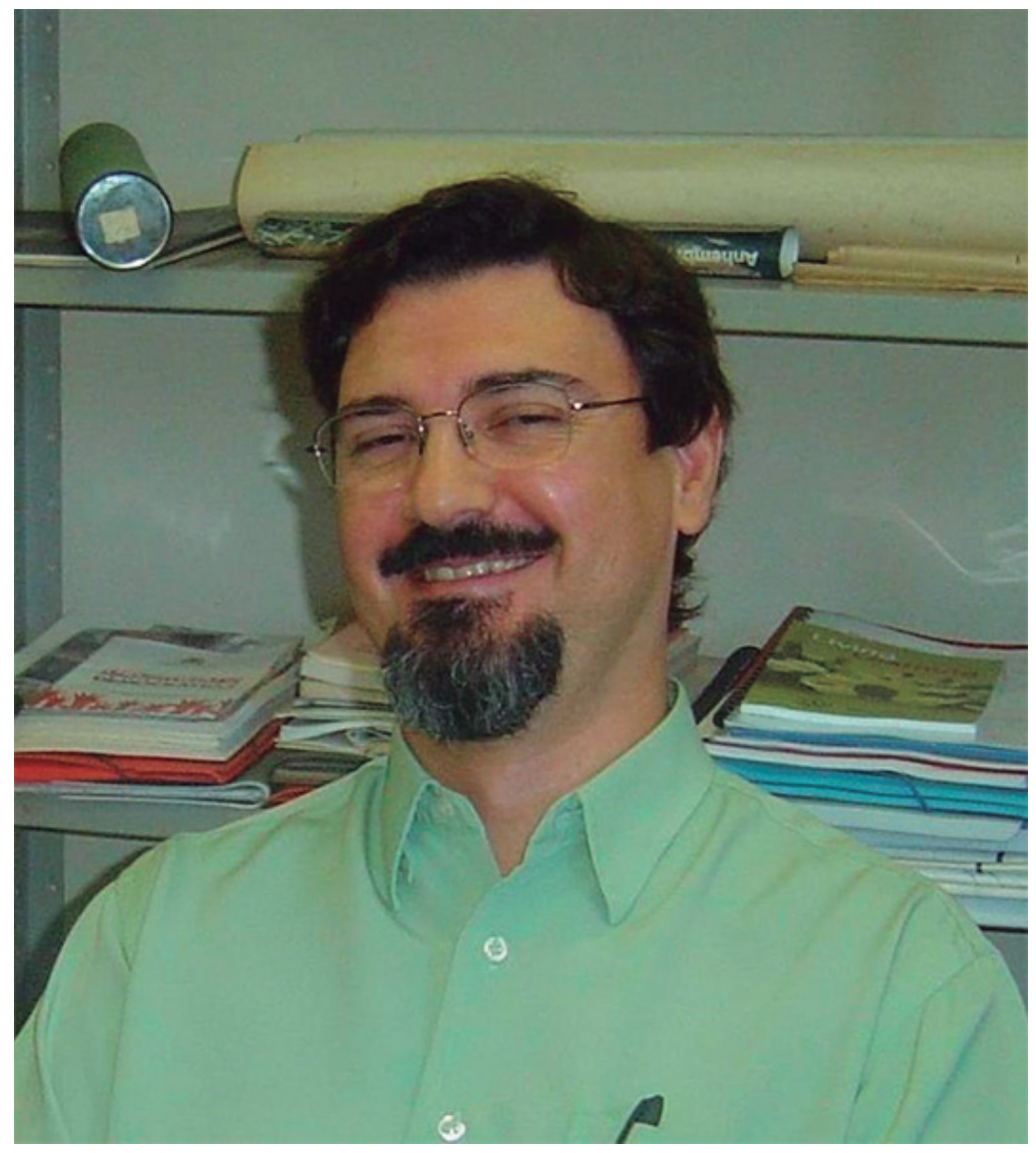

Figura 2. Marcelo Lopes de Souza en su centro de investigación (GAEP) en la Universidad Federal de Río de Janeiro.

VH: Gracias por responder estas dos preguntas de coyuntura actual. Estoy seguro que la actual pandemia y sus consecuencias globales han retroalimentado en algún sentido la perspectiva de la Geografía y de los propios geógrafos, así como su campo de investigación. Ahora quisiera realizarle unas preguntas sobre la Geografía y su producción académica.

En general, muchos investigadores y egresados de universidades de Latinoamérica ven a Brasil como un referente en ciencia y desarrollo académico; el reconocimiento de sus universidades a nivel internacional es expresión de ello. Imagino que la geografía y las carreras de grado relacionadas a esta ciencia se encuentran en ese mismo horizonte. En ese sentido, ¿Podría darnos un alcance sobre la situación actual de la Geografía en Brasil a nivel académico y de su relevancia en la sociedad brasileña? ¿Cómo ve a la Geografía en Brasil?

Es necesario considerar, preliminarmente, qué tipo de país es Brasil; sólo en este contexto será posible comprender las fortalezas y debilidades de la Geografía brasileña. En el marco del sistema mundial capitalista, Brasil es un país semiperiférico: es decir, combina, en medio de profundas contradicciones sociales, características que lo acercan a un país capitalista central (como la importancia y diversificación del sector industrial) y otras, más evidentes, que lo acercan a la situación de un país típicamente periférico (como las enormes desigualdades relacionadas con los ingresos, el acceso a la tierra y el porcentaje de hogares atendidos en términos de infraestructura básica). Es a la luz de estas contradicciones, propias de cualquier país semiperiférico, que es 
necesario tomar en cuenta la relativa sofisticación de una parte de las universidades brasileñas, en materia de investigación científica y tecnológica.

Sin embargo, no se puede perder de vista que las universidades brasileñas son un fenómeno relativamente reciente, ya que la colonización portuguesa prestó muy poca atención a la educación superior (la Universidad Mayor de San Marcos en Lima y la antecesora de la UNAM en la Ciudad de México son ambas de 1551, mientras que la primera universidad brasileña fue creada en 1912, a pesar de la existencia de algunas facultades de Derecho, Ingeniería y Medicina incluso antes). Los gobiernos brasileños, en general, continuando con una "tradición" del período colonial, prestaron poca atención a la educación superior; y, en los últimos años, con el ascenso de la extrema derecha al poder estatal en Brasilia y también en varios estados de la Federación, se ha acentuado el desinterés por las universidades e incluso la persecución a las universidades, por razones ideológicas. Por si fuera poco, es necesario no olvidar que las bases económicas de Brasil se han ido deteriorando: en las últimas tres décadas, Brasil se ha vuelto cada vez menos semiperiférico y cada vez más periférico, a raíz del proceso de desindustrialización y reprimarización de la economía. Es obvio que esto, a largo plazo, no ayudará a la investigación científica: no solo porque los recursos para la inversión en investigación serán más escasos, sino también porque el interés será menor - después de todo (así lo pensarán presidentes y gobernadores), ¿para qué sirve promover la investigación científica y tecnológica de vanguardia en un país cuyo PIB y cuyas exportaciones dependen cada vez más de la agroindustria y la minería?...

En el caso específico de la Geografía, finalmente, es necesario resaltar algunos factores que tornan a la Geografía brasileña algo peculiar, en el contexto latinoamericano. A pesar del carácter relativamente reciente de las universidades en Brasil, los cursos de Geografía comenzaron a implementarse temprano, según los estándares del "Sur Global": la Universidad de São Paulo fue creada en 1934, en gran parte por profesores franceses, y entre ellos también había geógrafos (como Pierre Deffontaines, reemplazado en 1935 por Pierre Monbeig); la Sección São Paulo de la Asociación de Geógrafos Brasileños (AGB), pionera de la AGB, fue fundada en el mismo año, 1934, por iniciativa de Pierre Deffontaines y algunos brasileños, como Caio Prado Júnior. En 1935 se fundó la Sección Río de Janeiro de la AGB, mismo año en que se inició el primer curso de Geografía en la Universidad del Distrito Federal (luego Universidad de Brasil, y actualmente Universidad Federal de Río de Janeiro). En 1938, cuando se graduaron los primeros geógrafos de la Universidad del Distrito Federal, se fundó el IBGE, que tuvo gran importancia para la Geografía brasileña: a pesar de ser, por excelencia, una "Geografía oficial", bajo el control directo del Estado, durante décadas, el IBGE fue también un centro de investigación relevante, que empleó a muchos geógrafos e invitó a geógrafos extranjeros a impartir clases e investigar (como el alemán Leo Waibel, el francés Michel Rochefort, el estadounidense Brian Berry y muchos otros). También es importante resaltar que la Geografía brasileña, a diferencia de la de algunos países de América Latina, no ha tenido prácticamente ninguna conexión con las instituciones militares desde la década de 1930; además, hace muchas décadas que también existe una clara diferenciación entre las profesiones de geógrafo e ingeniero cartográfico (bueno, esa diferenciación se ha vuelto más compleja en los últimos veinte años, con el auge de las "geotecnologías": geoprocesamiento, cartografía digital, etc.).

A pesar de todo esto, es importante evitar cualquier exageración con respecto a la Geografía brasileña; sobre todo, es fundamental rechazar toda y cualquier "mitificación" - de personajes individuales, pero también de la Geografía brasileña en su conjunto.

Por un lado, es innegable que la Geografía académica producida en Brasil ha jugado un papel importante en América Latina, especialmente bajo la influencia de Milton 
Santos (1926-2001). Milton Santos es un símbolo: el símbolo de una Geografía que no concuerda con los poderes despóticos y tiránicos (él se vio obligado a exiliarse después del golpe militar de 1964); de una Geografía que cultiva una mirada crítica e inconformista a la realidad de un mundo tan profundamente injusto y desigual como es el nuestro; y, finalmente, el símbolo de una Geografía producida desde el "Sur Global" que puede alcanzar un reconocimiento verdaderamente internacional. Además, en Brasil hoy hay cifras impresionantes: la cantidad de libros publicados por geógrafos brasileños ya se cuenta por cientos, hoy en día; el número de programas de posgrado es muy grande (hay alrededor de 70 maestrías y 50 doctorados); el número de revistas geográficas (muchas docenas) es igualmente notable; y finalmente, el tamaño de los congresos y simposios organizados por los geógrafos brasileños (que reúnen a miles de profesionales y estudiantes), sin mencionar la diversidad temática de los eventos (además de los congresos más generales, como los de AGB y ANPEGE, también pueden ser mencionados a los de Geografía Urbana [SIMPURBs], Geografía Agraria [ENGAs], Geomorfología, Geografía Física Aplicada, etc.).

Por otro lado, sin embargo, también me parece innegable que las contradicciones de un país semiperiférico se señalan de forma clara - directa o indirecta - en la Geografía brasileña de hoy. Es cierto que, en cierta medida, "hegelianamente", la cantidad genera calidad. Sin embargo, no podemos cerrar los ojos ante algunos problemas. Sin duda, existe un número considerable de destacados geógrafos brasileños, en algunos casos incluso a nivel internacional; por otro lado, las "cifras impresionantes" a las que me referí anteriormente no pueden ocultar grandes discrepancias y enormes déficits en términos de calidad y consistencia.

Para empezar, la Geografía brasileña es todavía muy "brasilocéntrica": la apertura a América Latina, por ejemplo, es reciente (viene, básicamente, de los últimos treinta años), y fue impulsada en gran medida por una iniciativa de Milton Santos. Además, los geógrafos brasileños, con algunas excepciones, aún publican muy poco en el exterior.

Es fundamental no confundir a Milton Santos con la Geografía brasileña, por varias razones. El hecho de que haya un gigante como él, con enorme influencia en América Latina, puede tentarnos a imaginar que la Geografía brasileña tiene una calidad académica proporcional al número de profesionales, cursos y revistas; esto, lamentablemente, no es cierto. De hecho, el carácter humano (y por tanto falible) de ese autor es algo que, por razones culturales y psicológicas, la Geografía brasileña (y quizás la Geografía latinoamericana en su conjunto) aún no está lista para reconocer, prefiriendo cultivar una especie de "personaje mitológico". Esto es comprensible; mucha gente necesita héroes o ídolos; sin embargo, precisamente desde un punto de vista crítico, adorar a alguien es siempre un obstáculo para el avance del conocimiento y el libre debate de ideas. El caso es que Milton Santos no es solo un símbolo, sino que también se ha convertido en un icono, lo que no es necesariamente positivo, ni intelectualmente ni, sobre todo, política y pedagógicamente. También porque es necesario destacar la presencia, entre las raíces de una Geografía crítica y original en América Latina, de varios otros buenos ejemplos - es decir, ejemplos de pioneros de una Geografía socialmente comprometida. Otros geógrafos y geógrafas de nuestro continente tuvieron un peso significativo y también alcanzaron el reconocimiento internacional (aunque, por distintas circunstancias biográficas, menor que el logrado por Santos), y no podemos olvidarlos: este es el caso, en Brasil, de Orlando Valverde (1917-2006), Manoel Correia de Andrade (1922-2007) y Aziz Nacib A'Saber (1924-2012); este es también el caso de la geógrafa chilena Graciela Uribe Ortega (1928-2000), quien trabajó durante muchos años en México luego de sufrir años de exilio en Europa tras el golpe de Estado liderado por Pinochet en 1973. Y podríamos seguir citando a otros ejemplos... 
Además, queda por examinar el hecho de que la Geografía brasileña necesita lograr mayor claridad sobre su responsabilidad ético-político-cultural. Los países semiperiféricos también tienden a ser subimperialistas, para usar la expresión de Ruy Mauro Marini (los conservadores hablarían de "potencias regionales"). La hegemonía imperialista no se limita al campo de la economía y las relaciones internacionales, sino que, tarde o temprano, también tiene implicaciones para las relaciones culturales y científicas; basta con ver la abrumadora influencia del cine y la música de Estados Unidos sobre el resto del mundo, así como la hegemonía de su producción científica. En lo que respecta al subimperialismo, estamos ante algo similar, aunque de mucha menor magnitud y de naturaleza más contradictoria. La Geografía producida en un país de este tipo se enfrenta a algunos dilemas y responsabilidades muy peculiares; cuanto más conscientes estén los geógrafos brasileños de esta situación, más consistente y coherente puede ser el conocimiento producido por ellos, especialmente en lo que respecta al conocimiento socialmente crítico.

Ahora bien, las relaciones asimétricas y subalternizantes no se dan solo a escala global, la del "Sur Global” frente al "Norte Global", teniendo el eurocentrismo como eje principal y, detrás, toda una historia de colonialismo, neocolonialismo, imperialismo y dependencia económica. En esta escala, los países del "Sur Global”, como los de América Latina, se enfrentan a la tendencia a la asfixia de sus culturas y tradiciones académicas, a favor de una "pasteurización epistémica" que viene tras la hegemonía no solo de la lengua inglesa y de las obras publicadas en inglés, pero también como consecuencia de la dominancia de una narrativa "angloamericana-céntrica" de la historia de la Geografía (y de la ciencia, la filosofía y la cultura en general) que eclipsa toda una historia de logros autóctonos en nuestro continente. Sin embargo, esta escala global está lejos de ser la única con la que tenemos que preocuparnos por las asimetrías, las desigualdades y las subordinaciones sociales, que también se verán reflejadas en múltiples niveles escalares de asimetrías académicas y subalternizaciones epistémicas. Dentro de cada país y, con sus propias características, también a nivel regional y local, encontramos disparidades económicas que tienen correspondencia y conexión con asimetrías de poder y subordinaciones culturales - "colonialismo interno", disparidades regionales, racismo, segregación residencial - qué siempre acaban teniendo algún tipo de conexión con estigmatizaciones, dominaciones y subordinaciones epistémicas. Una de las escalas con las que debemos aprender a lidiar es en realidad la de América Latina. La Geografía brasileña ha jugado un papel importante en diversas iniciativas y ha sido uno de los pilares de la renovación crítica de la Geografía latinoamericana; sin embargo, para que su presencia e influencia tengan un carácter emancipatorio, los geógrafos brasileños deben seguir esforzándose por mantener un verdadero diálogo y un intercambio horizontal con sus vecinos, y no ceder a la vanidad y la tentación de ser "líderes", reproduciendo en menor escala la búsqueda por la hegemonía que caracteriza a las Geografías del "Norte Global", especialmente (desde las décadas de 1960 y 1970) a la Geografía anglosajona - e incluso los geógrafos anglófonos críticos tienden a subestimar el problema del eurocentrismo... Finalmente, no necesitamos líderes: necesitamos compañeros (y ejemplos de coherencia ético-política-intelectual).

Con esto yo no quiero decir, obviamente, que haya una intención consciente, por parte de los geógrafos brasileños, de ejercer hegemonía epistémica; ¡mucho menos quiero decir que la Geografía brasileña es "subimperialista!" Pero lo cierto es que tampoco los geógrafos anglosajones tienen este tipo de intención consciente (al menos en el caso de los geógrafos críticos más coherentes), pero eso no elimina la existencia concreta de asimetrías y hegemonías. La cuestión es mucho más sutil. El filósofo inglés Edmund Burke era un conservador, lo que no me impide apreciar el valor de su frase: "lo único necesario para el triunfo del mal es que la gente buena no haga nada" (que, en el inglés original, tiene un tono tácitamente sexista, propio de la época: "The only thing necessary for the triumph of evil is for good men to do nothing"). En 
otras palabras, y adaptando el contenido del aforismo de Burke: no basta con que un geógrafo crítico rechace, en el campo de la retórica, las asimetrías y subalternizaciones. Para que haya una verdadera coherencia ético-política y práxica, los geógrafos y geógrafas verdaderamente comprometidos con un proyecto emancipatorio necesitan desarrollar una sensibilidad apropiada al diálogo intercultural, para inmunizarse contra el etnocentrismo y aprender a valorar la pluralidad de perspectivas y narrativas. Es decir, el carácter intrínsecamente plural de las Geografías, siendo cada una de ellas una respuesta a necesidades y condiciones específicas, en el marco de historias y culturas específicas - a pesar de las convergencias concretas y las solidaridades esenciales en un contexto común de explotación y opresión.

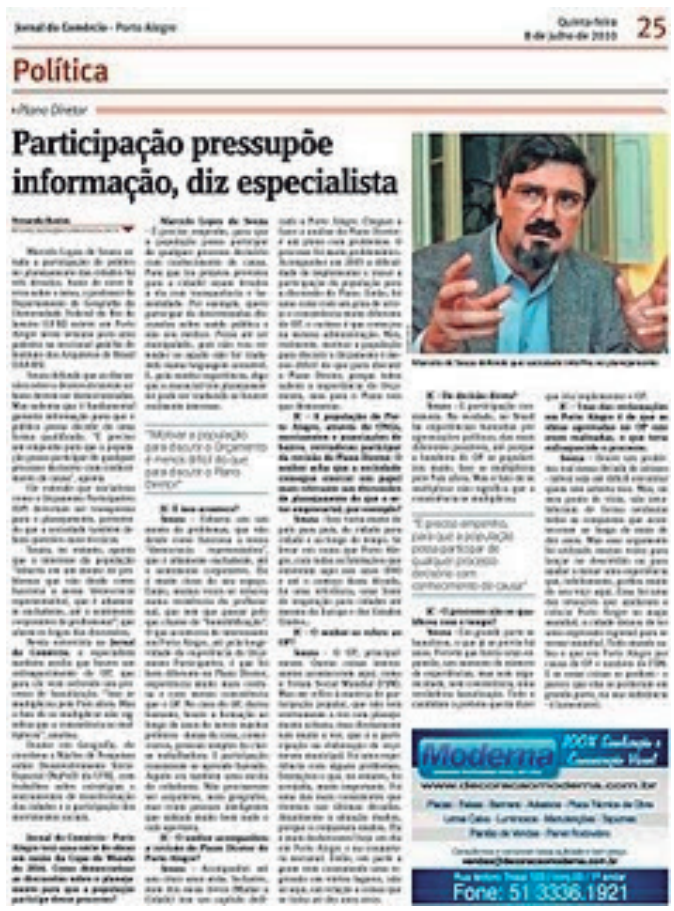

Figura 3. Marcelo Lopes de Souza ha buscado intervenir en debates públicos sobre diversos temas, desde la gestión urbana hasta la injusticia ambiental, a través de entrevistas y artículos para periódicos, revistas y sitios de Internet.

VH: Su interés académico y social se enfoca en la organización del espacio y su vínculo con los movimientos sociales, en los conflictos ambientales y en la justicia ambiental, en el contexto de la Ecología Politica y de la Geografía Ambiental. Estos temas distan mucho de la Geografía clásica, y me parece que le han generado una renovación a esta ciencia. ¿Podría comentarme un poco más sobre su producción académica y en que está enfocado actualmente?

En primer lugar, conviene decir algunas palabras sobre las limitaciones, pero también sobre las virtudes de la llamada Geografía clásica. Normalmente considero el período en la historia de la Geografía que se extiende desde aproximadamente la década de 1870 (que marca el comienzo de un proceso más consistente de institucionalización de la Geografía como disciplina académica) hasta las décadas de 1960 y 1970 (que es cuando la Geografía fue "sacudida", primero, por la "revolución cuantitativa", neopositivista, y, después, por el "giro crítico"). En el caso de Alexander von Humboldt y Carl Ritter, prefiero ver su tiempo como el último momento de la Geografía preclásica, por varias razones; una de ellas tiene que ver con el hecho de que la Geografía aún no estaba institucionalizada (desde la década de 1830 existieron las primeras 
"sociedades geográficas", pero la catedra (Lehrstuhl) de Ritter en Berlín se extinguió tras su muerte en 1859). Para Humboldt y Ritter, las distinciones entre "Geografía física" y "Geografía humana" todavía no surgieron, a pesar de las diferencias de énfasis, estilo e inclinación profesional: Humboldt era esencialmente un naturalista (aunque escribió sobre cuestiones políticas y sociales también), cuya investigación se basó, sobre todo, en el trabajo de campo; y Ritter, por su parte, fue, sobre todo, un estudioso que basó su idea de una Erdkunde o Geographie (una Geografía Regional en su esencia, y que fue muy influyente en cuanto a la orientación que seguiría la posterior "Geografía Humana", así como con respecto a la enseñanza de la Geografía en las escuelas) en un meticuloso trabajo de oficina, examinando fuentes e informes históricos y combinando la descripción y el estudio del asentamiento humano y la organización humana de la superficie terrestre con una seria consideración de las "bases físicas" (el relieve, los suelos, el clima, la fauna y la flora).

Ahora bien, la Geografía clásica, a diferencia de la época de Humboldt y Ritter, ya conocía una distinción entre "Geografía Humana" y "Geografía física" - y esta diferencia se hizo cada vez más clara a medida que ingresaba al siglo XX. Sin embargo, distinguir no es lo mismo que separar: los cánones clásicos abogaban por el intercambio constante e incluso la cooperación entre geógrafos "físicos" y "humanos". Es cierto que el modelo no se siguió de manera exacta y simétrica: los "geógrafos humanos", siempre atentos a las "bases físicas", se interesaron por el conocimiento generado por los "geógrafos físicos" con mayor frecuencia e intensidad que en el caso inverso. A pesar de ello, podemos decir que la Geografía clásica, al presentarse como una "ciencia-puente" entre el estudio de la naturaleza y el estudio de la sociedad, no fue un fraude. Sin embargo, la "síntesis" que prometió realizar era, desde la perspectiva actual, superficial; y su desdén por teorizar (la Geografía debería ser una "ciencia de lo concreto", como orgullosamente sentenciaba Jean Brunhes) nos suena ingenuo. El esfuerzo por integrar dimensiones y factores realizado por la Geografía clásica se vio muy obstaculizado por el empirismo y el funcionalismo, y la "síntesis", en cierto modo, fue, ante todo, un "sincretismo" cuya consistencia epistemológica, teórica y metodológica se reveló, a más tardar en los años sesenta y setenta, insuficiente y frustrante.

Bien, fue precisamente este empirismo el que hizo que la Geografía clásica se orientara por temas (y por el intento de describir y explicar "todo" con respecto a un determinado "paisaje" o "región"), y no precisamente por problemas. En el marco de una concepción funcionalista de la realidad, que iba de la mano con una cosmovisión típicamente conservadora (geógrafos como los anarquistas E. Reclus y P. Kropotkin fueron excepciones, que como resultado de sus posiciones políticas fueron marginados), no es de extrañar que los movimientos y los conflictos sociales no habían sido temas valorados en el ámbito de la Geografía clásica. Esto solo comenzó a cambiar, de manera más masiva, a partir de la década de 1970, con el "giro crítico" (que fue, en el fondo, un "giro marxista", ya que el pensamiento libertario permaneció, hasta principios del siglo XXI, casi invisible, segregado por la nueva corriente dominante neomarxista).

Desafortunadamente, sin embargo, la abrumadora mayoría de geógrafos críticos de los años setenta y ochenta cometieron el error de - discúlpeme ahora si utilizo una frase común - "tirar al bebé con el agua sucia". Ajena a lo que ya se mostraba, en la década de 1970, como una presencia cada vez más clara de los problemas ambientales en la agenda política de gobiernos, organizaciones supranacionales y movimientos sociales, la mayoría de los geógrafos humanos decidieron apostar por lo que Bruno Latour llamó "purificación" (epistemológica), en lugar de valorar los objetos epistémicos híbridos. Deseosa de poder ser aceptada como ciencia social y no más tratada como un paria en la constelación de las ciencias de la sociedad, la Geografía Humana de inspiración (neo)marxista comenzó a descuidar e incluso a desdeñar las preocupaciones sobre factores, dinámicas y procesos geobiofísicos. Así, curiosamente, 
estos geógrafos humanos simplificaron demasiado el legado del propio Marx, que nunca rechazó el interés por las ciencias naturales. Es como si la historización de la naturaleza, en sí misma válida y necesaria, sólo pudiera hacerse a costa de un total abandono del interés por el condicionamiento relativo y la materialidad de los suelos, el relieve, el clima, etc., con todos los procesos físicos, químicos y biológicos que subyacen a su evolución. El miedo al "determinismo geográfico" y, además, la crítica pertinente al funcionalismo y al empirismo de la idea vidaliana de "región", de la noción de Landschaft (bastante inexactamente traducible como "paisaje") de la Geografía alemana clásica y de tantos otros constructos frágiles, se complementó con algo que no tenía por qué haber sucedido: un cierto complejo de inferioridad hacia los sociólogos, economistas, etc., llevó a muchos geógrafos humanos a avergonzarse de su pasado y de su identidad. Por su parte, la Geografía Física, que se había ido fragmentando y alejándose de la Geografía Humana desde antes de la Segunda Guerra Mundial, aceleró esta distancia. En la década de 1980, parecía que la brecha dentro de la disciplina era un camino sin retorno.

Afortunadamente, algunos geógrafos han reaccionado, negándose a aceptar la pulverización de la Geografía como algo inevitable. Desde las décadas de 1980 y 1990, varios geógrafos se han "refugiado" más o menos explícitamente en la Ecología Política; esto se aplica no solo al ambiente intelectual de habla inglesa, sino también al latinoamericano (por ejemplo, Carlos Walter Porto-Gonçalves, en Brasil, y Georgina Calderón Aragón, en México; y, más recientemente, María Gabriela Merlinsky y Horacio Machado Araoz, en Argentina - para quedarnos sólo con unos pocos ejemplos). La Ecología Política, sin embargo, es un campo interdisciplinario. Muchos comenzaron a darse cuenta de la importancia de una disputa epistémico-discursiva dentro de la Geografía misma. Más recientemente, de esta forma, el intento de recuperar, para la Geografía, el derecho a construir objetos epistémicos híbridos ha ido ganando fuerza en un intento que se ha denominado Geografía Ambiental. He argumentado, de hecho, en artículos y libros, que la Geografía Ambiental no es una nueva "rama", una subdisciplina, sino más bien un enfoque, una perspectiva, una forma de mirar la realidad; o, más precisamente, la sinergia derivada del encuentro de dos perspectivas, la ecogeográfica (para recordar la expresión Ecogeografía, de Jean Tricart) y la sociogeográfica (para usar la expresión Geografía Social, introducida hace más de un siglo por E. Reclus). Estas dos perspectivas, cabe señalar, no constituyen un dualismo, sino una dialéctica: aunque reconocemos diferencias epistemológicas (e incluso ontológicas), lo que evita una uniformidad metodológica - no entenderemos la dinámica de los procesos geobiofísicos utilizando etnografías y el análisis de discurso, así como no esclareceremos la dinámica de la valorización capitalista del espacio o las relaciones de poder involucradas en la organización espacial utilizando los métodos de las ciencias naturales -, sostenemos que es posible y necesario combinar datos e información y, en la medida de lo posible, comparar e integrar conceptos y articular teorías, por diferentes que sean. No es fácil (sobre todo porque hemos descuidado esta tarea durante décadas), pero está lejos de ser imposible.

Mi trabajo ha girado en torno a la Geografía Ambiental y la Ecología Política, enfocándome principalmente en problemas y conflictos urbanos. El foco principal de mis esfuerzos ha sido, principalmente, la discusión de la injusticia ambiental, en el marco de la discusión de la injusticia social, así como la consideración de la dimensión de la injusticia ecológica. Es en este contexto que he realizado investigaciones empíricas que han implicado la movilización de conceptos y enfoques relacionados con la producción social de riesgos y desastres, el "sufrimiento ambiental" (concepto que ha sido introducido por colegas argentinos) y los conflictos, al mismo tiempo que he buscado discutir teorías y conceptos $-\mathrm{y}$, a partir de todo ello, alimentar mi reflexión sobre la Geografía, sus limitaciones y potencialidades. 
Todo esto lo he hecho solo o con la ayuda de mis alumnos y estudiantes de maestría y doctorado, pero también, en ocasiones, en cooperación con compañeros geógrafos que han tenido una trayectoria profesional completamente diferente a la mía. Así ha sido con el agrogeógrafo y biogeógrafo Luciano Candiotto, en el contexto de un proyecto de investigación sobre las potencialidades y limitaciones de la agroecología, entre otras situaciones de colaboración; y así también ha sido con la geomorfóloga e hidrogeógrafa Adriana Filgueira Leite, en el marco de una cooperación para el estudio de la hidropolítica en la región norte del estado de Río de Janeiro (en la que las élites rurales locales han estado manipulando, durante muchas décadas, el sistema de canales de riego implementado por el Estado en beneficio propio y muchas veces en detrimento de intereses de la mayor parte de la población). Mi libro más reciente - Ambientes y territorios: Una introducción a la Ecología Política - sintetiza muchas de mis reflexiones teórico-conceptuales, a menudo bajo inspiración de mi experiencia también con investigaciones empíricas concretas. Lo mismo puede decirse, de hecho, de otros trabajos míos, como por ejemplo mi libro Los conceptos fundamentales de la investigación socio-espacial, escrito para estudiantes de pregrado.
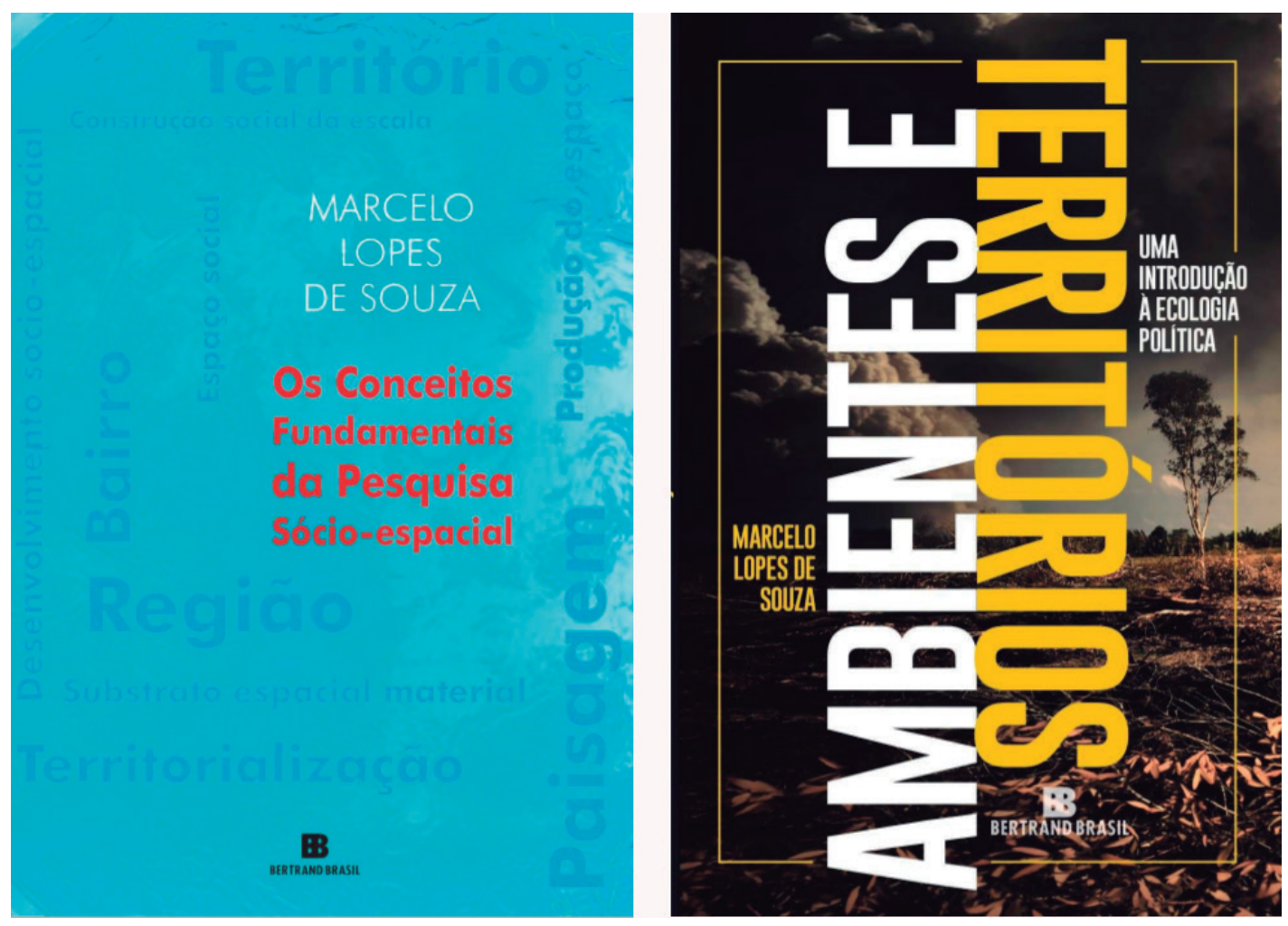

Figura 4. "Los conceptos fundamentales de la investigación socio-espacial” (izquierda), publicado en 2013. “Ambientes y territorios: Una introducción a la Ecología Política”, publicado en 2019 (derecha).

VH: Parte de su producción académica está enfocada en la Geografía y el pensamiento libertario, donde rescata las ideas de Eliseo Reclus y Piotr Kropotkin, entre otros. Su libro "Por una Geografía libertaria" (2017) aborda esta perspectiva. ¿En qué se diferencia la Geografía libertaria de "otras Geografías"?

En primer lugar, me gustaría aclarar que el adjetivo "libertario", a mi entender, abarca mucho más que el anarquismo, y sobre todo más que el anarquismo clásico (que es, sin embargo, el más antiguo representante e histórica y políticamente el más conocido ejemplo del pensamiento y de la praxis libertarios). La "galaxia libertaria" o "familia libertaria" engloba varias corrientes y tendencias, desde el anarquismo clásico (que básicamente se extendió entre mediados del siglo XIX y mediados del 
$\mathrm{XX)}$ y las corrientes neoanarquistas de la segunda mitad del siglo $\mathrm{XX}$ y principios del XXI (como la social ecology de Murray Bookchin) hasta el "proyecto de autonomía" de Cornelius Castoriadis (que me ha influido mucho desde mediados de los ochenta). Además, movimientos sociales como los neozapatistas mexicanos y una parte de los piqueteros argentinos pueden, en mi opinión, ser vistos como ejemplos de principios y praxis libertarios.

Lo que tienen en común los diversos representantes del pensamiento y la praxis libertarios es un rechazo simultáneo del capitalismo (y del Estado capitalista, por supuesto), por un lado, y del "socialismo burocrático" al estilo leninista, por el otro. En realidad, la crítica de los libertarios al centralismo, la ambigüedad frente al "Estado" y el economismo no se limita al leninismo, y mucho menos al estalinismo: desde Proudhon y Bakunin se han hecho importantes objeciones a algunos aspectos del trabajo teórico y actuación política de Marx mismo. A pesar de esto, los libertarios y marxistas de hoy necesitan encontrar formas de dialogar honestamente $\mathrm{y}$, eventualmente, cooperar de manera constructiva, porque los desafíos y enemigos comunes - por ejemplo, el surgimiento de nuevos nacionalismos y el neofascismo que se extiende por todo el mundo - son, hoy, más importantes que lo que separa estas dos grandes corrientes del pensamiento crítico de los dos últimos siglos. Además, algunos marxistas han aprendido de las lecciones del pasado, incluido el enfoque de principios y estrategias como la autogestión, defendidos desde el siglo XIX por los libertarios (desafortunadamente, sin embargo, no es común que los marxistas den el debido crédito o reconocimiento a los libertarios, lo que dificulta mucho el diálogo).

Una "Geografía libertaria", en definitiva, es una Geografía crítica y pluralista que, aunque radical en términos de objeciones al capitalismo, también se aleja de las falsas "soluciones" basadas en la centralización y los métodos verticales; es también una Geografía que, sin negar la importancia crucial de la explotación del trabajo y la lucha de clases, se abre a la consideración profunda de otras formas de opresión, como el racismo y el sexismo, sin subordinar la explicación de su dinámica (y su superación) enteramente a los problemas económicos y de clase social.

Hay varias diferencias entre la mirada libertaria y la mirada típica del marxismo (y yo no hablo solo del marxismo ortodoxo). A veces son diferencias de énfasis, pero a veces son más profundas. Algunos ejemplos:

1. Los movimientos sociales, aunque han sido estudiados en profundidad por muchos investigadores marxistas durante mucho tiempo, no siempre han sido analizados sin incrustar supuestos teóricos o políticos problemáticos, como un cierto economicismo y la marginación de todo lo que no está directamente vinculado a la lucha de clases. De ahí la dificultad de valorar adecuadamente agendas como la lucha antirracista y antisexista.

2. La cuestión ecológica (es decir, el conjunto de problemas derivados del carácter antiecológico del modo de producción capitalista) ha sido tomado muy en serio por algunos pensadores y teóricos marxistas, como Elmar Altvater, Robert Biel, John Bellamy Foster, Enrique Leff y Jason Moore; algunos geógrafos marxistas, especialmente aquellos vinculados a la Ecología Política, también han prestado atención al tema durante mucho tiempo. Sin embargo, la postura de Marx hacia las fuerzas productivas capitalistas estuvo marcada por la ambigüedad: su crítica se centró en las relaciones de producción, pero, en última instancia, su visión de la tecnología heredada del capitalismo fue bastante benevolente. Además, como hijo de la Ilustración y del siglo XIX (el "siglo del progreso"), Marx no rompió claramente con el proyecto (profundamente capitalista) de una "dominación de la naturaleza". Todo ello, en el marco del economicismo y el productivismo (creencia en la expansión ilimitada de las fuerzas productivas) que caracterizó 
al pensamiento de Marx, hace de una crítica ecológica al capitalismo, por parte de los marxistas, una tarea que no es fácil de emprender con coherencia. Una perspectiva como la ecología social del neo-anarquista Murray Bookchin, por ejemplo, se enfrenta mucho menos al riesgo de inconsistencias.

3. Otro tema que los marxistas tienen dificultades para abordar (o que a menudo ni siquiera están interesados en abordar) es el de los derechos de los animales y, más ampliamente, el de la justicia ecológica. Sus contribuciones a la justicia social e incluso a la justicia ambiental han sido significativas, pero un antropocentrismo exacerbado los hace resistentes a dar importancia a las cuestiones éticas (y políticas, y también económicas) relacionadas con los vínculos complejos entre humanos y no humanos.

4. Otro tema en el que el pensamiento libertario tiende a diferir del marxismo (y más aún del pensamiento liberal) se refiere a la crítica al eurocentrismo. El marxismo ha construido un marco teórico-conceptual impresionante y muy rico, y desde él se han ofrecido varias contribuciones relevantes, desde un punto de vista emancipatorio. No hay duda de ello. A pesar de ello, la mirada marxista típica ha sido, casi siempre, de exaltación de lo urbano, las ciudades y la urbanización, en el marco de una perspectiva muy eurocéntrica: por mucho que se analice la desigualdad en todas las escalas, por mucho que se denuncie el imperialismo y por mucha solidaridad que se manifieste con respecto a los campesinos, los pueblos originarios y las poblaciones tradicionales, los principios y criterios de análisis están, sobre todo, influidos por una cierta herencia de la Ilustración y del pensamiento colonial: el proyecto de modernidad. A menudo existe una falta de una sensibilidad más profunda para valorar realmente la diversidad de pueblos, culturas y modos de vida. Veamos, por ejemplo, las discusiones sobre el "derecho a la ciudad", de Lefebvre, y que se desarrollaron en la tesis de la "urbanización planetaria", de Neil Brenner y otros: la urbanización no se ve solo como un proceso real, que está en marcha, y en cuyo contexto campesinos y poblaciones tradicionales son desterritorializados y reducidos a la condición de trabajadores urbanos explotados y residentes de espacios informales estigmatizados y segregados; de hecho, la urbanización se ve como algo intrínsecamente positivo (tanto como se reconocen obviamente las desigualdades e inequidades de la urbanización capitalista), y lo que no es "urbano" (en el sentido occidental) se trata como mero anacronismo. Esta forma de ver las cosas es extremadamente eurocéntrica, aunque los investigadores no se dan cuenta (o no quieren darse cuenta...) de ello. La dimensión teleológica/historicista del pensamiento de Marx ciertamente influyó en esta forma de tratar la historia y las culturas, en cuyo contexto la apertura a la pluralidad de modos de vida acaba siendo, en general, pequeña.

Podría seguir ofreciendo ejemplos, pero creo que estos ya son suficientes para mostrar algunas particularidades del pensamiento libertario frente al marxista, lo cual se refleja en la forma en que se puede hacer la Geografía bajo la inspiración de cada una de estas grandes matrices teórico-político-filosóficas.

Yo diría que las tareas de los geógrafos y geógrafas libertarios de hoy son mejorar y actualizar constantemente su análisis crítico del capitalismo (iy no solo del neoliberalismo!) y del neofascismo contemporáneo, mientras dialogan constructivamente con el pensamiento marxista y también con otras corrientes y autores del pensamiento crítico (como Michel Foucault y, en nuestros días, Giorgio Agamben y Achille Mbembe, por ejemplo). 


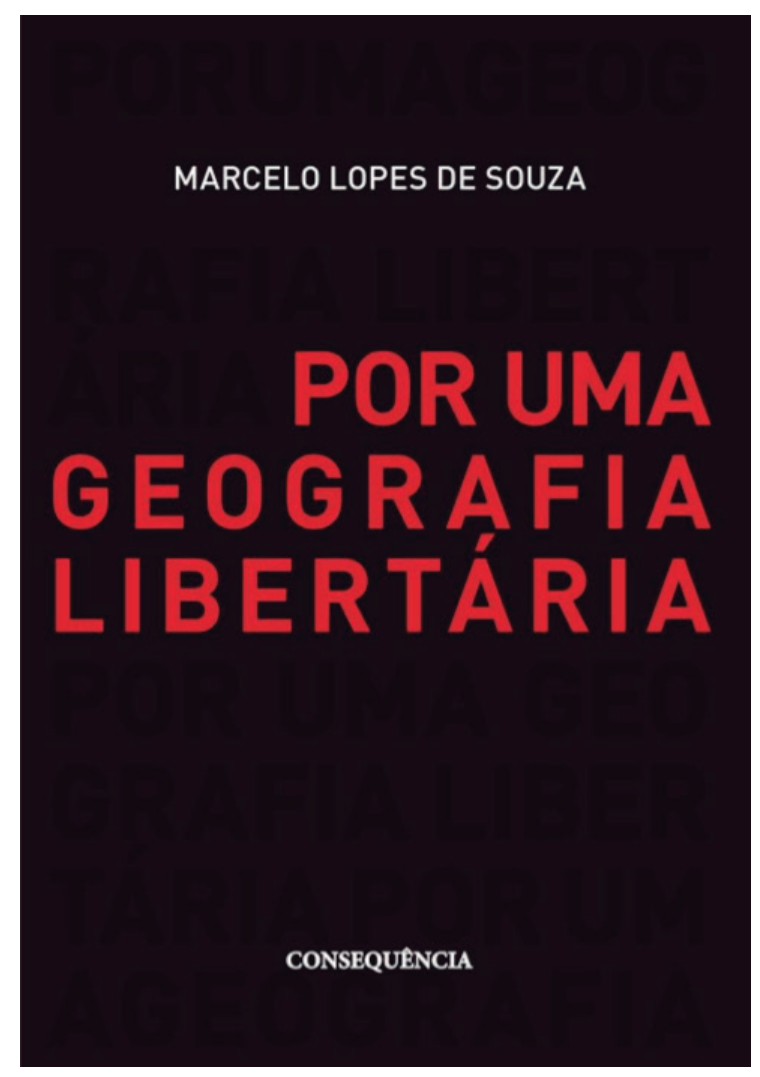

Figura 5. "Por una Geografía libertaria”, publicado en 2017.

VH: En algunas de sus publicaciones escribió intensamente a cerca de la Geografía Ambiental. ¿Qué plantea en relación a este tema? ¿Esta temática es nueva para la Geografía?

Vamos a empezar con la cuestión de la historicidad de la propuesta. Es muy difícil, quizá imposible, situar con precisión el momento de la emergencia desde la perspectiva que se conoce, en varios idiomas, bajo el nombre de "Geografía Ambiental". Intentarlo siempre implicaría una dosis excesiva de arbitrariedad. Podemos, en cambio, con más modestia, pero también con más realismo, postular algunos marcos temporales (y algunos criterios).

Primero, es necesario reconocer que, en el contexto de la geopolítica internacional de la producción y circulación del conocimiento científico/académico, la Geografía Ambiental ha adquirido una visibilidad significativa y creciente porque el debate sobre una environmental geography ha sido estimulado y catalizado por el ambiente intelectual Anglosajón - que es el gran "exportador de agendas de investigación" de las últimas seis décadas, tanto en Geografía como en tantas otras áreas del conocimiento. Sin embargo, asumir que la Geografía Ambiental surge solo cuando los colegas de habla inglesa comienzan a promoverla, correspondería a una vez más introyectar a la vieja y (a menudo lamentada de manera puramente retórica) subalternización colonial, aceptando ciegamente la narrativa de estos colegas (notoriamente provincianos desde el punto de vista lingüístico-cultural).

De hecho, si prestamos atención a lo ocurrido en Brasil en las últimas décadas (para quedarnos, inicialmente, en un solo ejemplo), veremos que, a pesar de no encontrar ningún uso sistemático de la expresión "Geografía Ambiental", un tipo de conocimiento clasificable de esta manera nunca ha dejado de estar presente. De Orlando Valverde (representante de una geografía "tradicional" o "clásica" que, sin embargo, continuó ofreciendo importantes trabajos en el espíritu de un "diálogo de saberes intradisciplinario" casi hasta su muerte en 2006) a Carlos Walter PortoGonçalves (practicando igualmente una "transversalidad epistémica", pero de una 
manera renovada discursivamente por el soplo de aire fresco de la "Geografía crítica" de los años 1970 y 1980), la década de 1980 - que fue la década de consolidación del desprecio recíproco entre los geógrafos "humanos" y "físicos" - nos legó, a pesar de las tendencias imperantes del diálogo menguante, obras notables que se pueden entender perfectamente como Geografía Ambiental (o incluso Ecología Política). Si hacemos el ejercicio de mirar a otros países, comenzando por los países europeos que han hegemonizado la "tradición geográfica" durante más de un siglo - Alemania y Francia -, y si los comparamos con las peculiaridades de la producción anglosajona, encontraremos que ellos también, cada uno de ellos a su manera, no se mostró simplemente como un satélite o caja de resonancia para esta producción, a pesar de que han sido fuertemente influenciados por ella durante varias décadas.

Con esto, lo más justo y riguroso parece consistir en lo siguiente: ver a la Geografía Ambiental como algo que se fue modelando paulatinamente, muchas veces de forma poco consciente y sin preocupaciones por los nombres, en medio de una resistencia multifacética y más o menos explícita al rechazo de un "diálogo de saberes intradisciplinario" - rechazo típico de las décadas de 1970 y 1980, a raíz del "giro crítico" de la disciplina. Paralelamente, a partir de finales del siglo XX o principios del XXI, los geógrafos de habla inglesa (ya vinculados o no al campo interdisciplinario de la Ecología Política) comenzaron a poner sobre la mesa la propuesta de una environmental geography, posiblemente condicionando (y a veces meramente catalizando algo que ya estaba en marcha) un movimiento similar en varios otros países. Por mucho que haya una producción de "resistencias" en las décadas de 1980 y 1990, las dos primeras décadas del presente siglo son, por tanto, una referencia temporal fundamental.

Todo esto me lleva a la pregunta: ¿es, después de todo, nada más que "vino viejo en una botella nueva"? Sí, hay una novedad innegable, explicable a la luz de los debates epistemológicos, teórico-conceptuales y metodológicos del último medio siglo. Al mismo tiempo, sin embargo, las raíces son muy antiguas, además de la existencia de varios hilos de continuidad, en los países más diversos. El contexto histórico, primero de los últimos cincuenta o sesenta años, y luego, más particularmente, de las últimas dos décadas, marca la diferencia, en comparación con el "vino" (hasta cierto punto muy sabroso, a pesar de sus defectos como el empirismo y el funcionalismo) que correspondía a la denominada Geografía "clásica" o "tradicional".

Yo creo que es posible resumir la cuestión de la relativa novedad de la Geografía Ambiental en términos de dos características:

Primera novedad: sofisticación teórico-conceptual, superación del desprecio empirista por la teorización y gran apreciación del intercambio interdisciplinario. Esto es, precisamente, una parte sustancial de lo que trajo el "giro crítico" de los años setenta y ochenta. Las principales características son: 1) partir de problemas, en lugar de simplemente delinear temas, para luego describir y catalogar empíricamente a las cosas; 2) explicar y reflexionar en profundidad sobre las bases teórico-conceptuales y metodológicas, sus potencialidades y limitaciones. A estos requisitos, la Geografía Ambiental añade un tercero: valorar la construcción de objetos de conocimiento híbridos con plena conciencia de los límites de integración de datos, información y matrices teóricas.

Segunda novedad: modestia epistemológica; quiere decir, el enfoque de Geografía Ambiental es un esfuerzo de legitimación epistémica de los híbridos que no aplasta al Otro - en otras palabras, que no anula los objetos epistémicos que no son explícitamente o fuertemente híbridos. Por un lado, es bastante cierto que no son sólo los objetos de conocimiento explícitos y fuertemente híbridos los que no deben ignorar el entrelazamiento visceral de "naturaleza" y "sociedad". Ninguna investigación en Geografía (o en cualquier área) puede permitirse ignorar eso: a pesar de las diferencias ontológicas (con consecuencias epistemológicas y metodológicas) entre la sociedad (o sea, la "naturaleza segunda") y la naturaleza no humana (o sea, la "primera 
naturaleza"), no hay una separación. Por otro lado, son legítimas las investigaciones de problemas relacionados con fenómenos como, por ejemplo, la espacialidad del comportamiento electoral o las identidades socio-espaciales - temas que no plantean la necesidad de una integración teórico-conceptual o metodológica (y en general ni siquiera de resultados empíricos) entre investigación sociogeográfica y ecogeográfica.

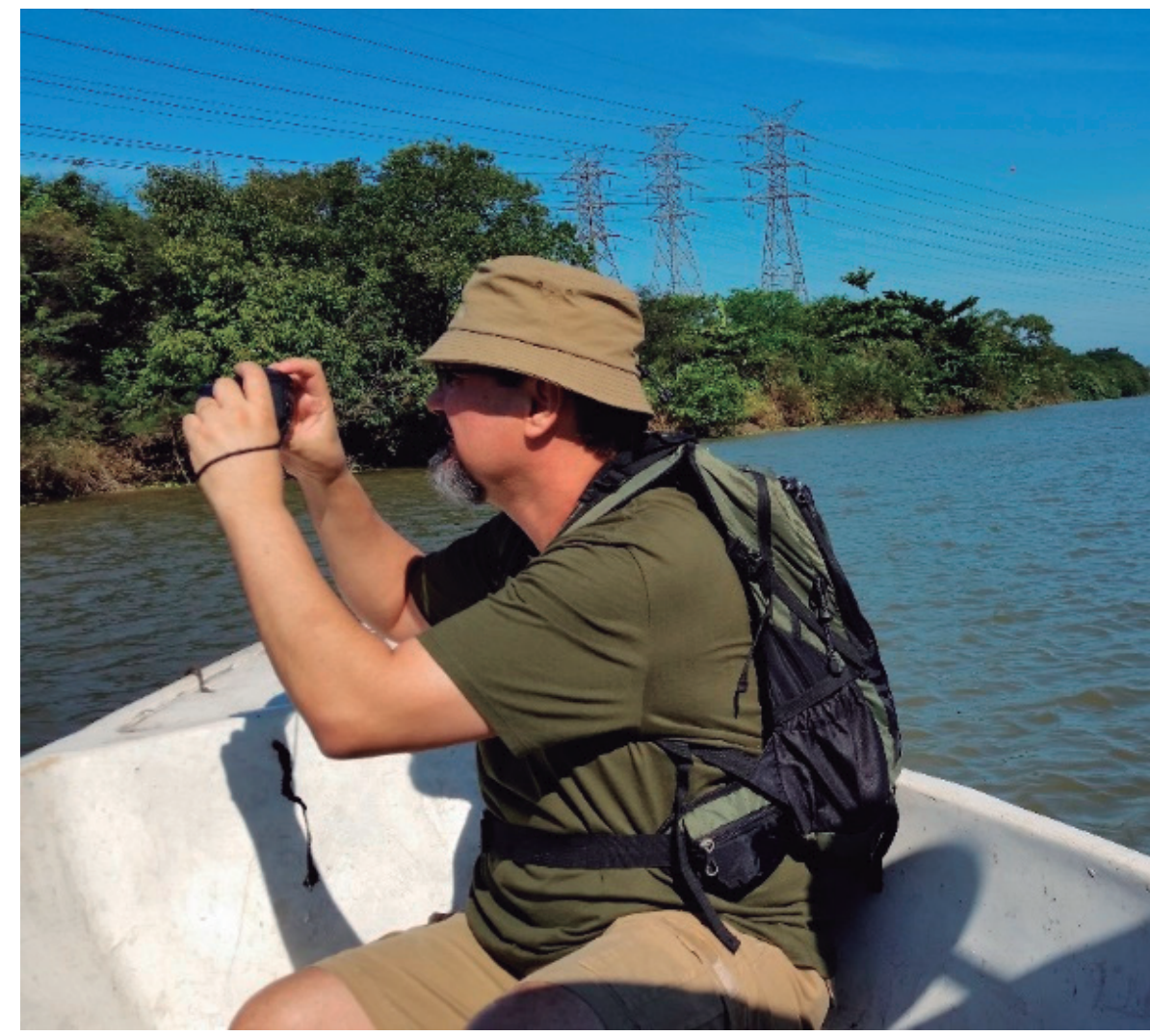

Figura 6. El entrevistado durante un trabajo de campo (2019) en la desembocadura del río Guandú (Zona Oeste de Río de Janeiro), investigando la contaminación provocada por una empresa siderúrgica y la consecuente situación de sufrimiento e injusticia ambiental.

VH: Antes de realizarle la última pregunta, deseo darle las gracias por acceder a esta entrevista y por compartir sus ideas y pensamiento sobre esta ciencia tan apasionante. Por mi parte, al escuchar sus respuestas, más que una entrevista, ha sido un aprendizaje. Finalmente, ¿Cuál es su perspectiva sobre la Geografía para los próximos años? ¿En qué debemos enfocarnos?

Hacer predicciones es muy arriesgado; y tratar de definir las tareas de la Geografía para las próximas décadas sería un ejercicio demasiado arrogante, si no tonto. Por eso, prefiero ser más prudente y limitarme a llamar la atención de mis colegas sobre algunos desafíos que no se pueden ignorar.

La Geografía se ha vuelto, en las últimas décadas, mucho más plural, tanto teórica como políticamente, de lo que había sido hasta la década de 1980. Esto, en principio, es algo muy positivo, y que demuestra la vitalidad de nuestra profesión. Sin embargo, al mismo tiempo, hay dos cosas que, en mi opinión, son preocupantes o incluso muy preocupantes.

La primera cosa es la fragmentación epistemológica de la Geografía (o quizá su pulverización), que es una tendencia que ha avanzado mucho; la fragmentación interna de la Geografía Física comenzó antes de la Segunda Guerra Mundial, y en los últimos treinta años la Geografía Humana también se ha fragmentado. Es muy 
común, hoy, que los geógrafos urbanos y agrarios no conversen, como es común para los geógrafos culturales dialogar mucho más con los antropólogos que con otros geógrafos; o el caso de los geógrafos económicos, que a menudo casi sólo dialogan con los economistas; o el caso de los geógrafos políticos, que están mucho más involucrados en los debates de las Ciencias Políticas y de la Filosofía Política que con las discusiones de los otros geógrafos. En medio de todo esto, se hace un esfuerzo por volver a plantear la cuestión de la necesidad de integración, hacia una valorización de la construcción de objetos epistémicos híbridos, es decir, el esfuerzo por construir la Geografía Ambiental, así como para estimular los aportes de los geógrafos para el campo interdisciplinario de la Ecología Política.

La segunda tendencia que me preocupa, y que es mucho más grave, es la que concierne al crecimiento del conservadurismo e incluso de la extrema derecha y el neofascismo en el mundo contemporáneo. La Geografía, que sigue siendo una trinchera importante en términos de pensamiento crítico, ciertamente no es inmune a los reveses políticos. Es posible construir el escenario de una creciente polarización político-ideológica dentro de la disciplina para los próximos años. Al mismo tiempo, y precisamente por ello, los geógrafos necesitan reforzar los lazos de cooperación activa con los movimientos y activismos sociales emancipatorios que tienen el objetivo de enfrentar las desigualdades; por ejemplo, los activismos involucrados con la denuncia y la lucha en contra de situaciones concretas de injusticia ambiental. No es suficiente que los geógrafos investiguen los movimientos, y no es suficiente ofrecer a los movimientos una mera solidaridad retórica; lo que realmente importa es la capacidad de los geógrafos para desarrollar conocimientos socialmente útiles y colaborar con luchas reales. 